\title{
ENFERMERÍA: UNA PROFESIÓN DIGNA Y POCO VALORADA ENFRENTANDO AL COVID 19
}

\author{
Nursing: A profession Worthy and Little valued facing COVID 19
}

Mg. Marlene Elizabeth Muñoz Aguirre ${ }^{1}$

${ }^{1}$ Docente asociado de la Facultad de Enfermería, Universidad Nacional San Luis Gonzaga. Ica, Perú. Magíster en Salud Pública.

"EI COVID-19 es una enfermedad infecciosa causada por el virus SARS-CoV-2, iniciándose en China y surge en el año 2019 (1), el cual produce el síndrome respiratorio agudo grave desencadenando una neumonía grave sobre todo en adultos mayores o pacientes que presentan comorbilidad como la obesidad, hipertensión, diabetes. Debido a su creciente diseminación en todo el mundo la Organización Mundial de la Salud la considero como una pandemia el 11 de marzo del 2020" (2). Estamos enfrentando un año muy difícil de lucha contra un virus invisible y devastador, que ha producido la muerte de muchas personas a nivel mundial, entre ellos profesionales de la salud como enfermeros(as) que cuidan de la vida de sus pacientes, los cuales fueron contagiados por la irresponsabilidad e imprudencia de algunas personas que no guardaron la cuarentena, inadecuadas políticas de gestión de las autoridades, logrando que el virus se replicara velozmente e incremente la carga viral, en las calles y hospitales de la región llegando incluso al colapso hospitalario.

"Actualmente el profesional de salud, en la lucha contra el coronavirus puede experimentar diferentes problemas, afectando principalmente su salud mental, provocando estrés, síntomas de depresión, ira, insomnio y ansiedad. Estas afecciones a la salud mental no solo tienen un impacto significativo en la calidad de la atención que brinda el profesional sino también afecta sus habilidades en el cumplimiento de sus deberes, siendo necesario e importante proteger la salud mental del profesional de salud"(3).En este sentido las enfermeras permanecemos 12 a 24 horas cuidando y salvando la vida de los pacientes, muchas veces llegando a trabajar hasta el límite de nuestras fuerzas, porque no hay personal, ya que las colegas se contagiaron y están guardando aislamiento, algunas en $\mathrm{UCl}$ luchando por sus vidas y otras que partieron al descanso eterno, profesionales que murieron por atender a un paciente COVID 19 positivo. Las enfermeras poseemos profesionalismo, capacitación, entereza y vocación de servicio para brindar una atención de calidad en la búsqueda de su recuperación física y emocional. Pocas veces se reconoce nuestro trabajo sacrificado de horas continuas, durante la jornada laboral no solo como enfermeras asistenciales, también desempeñando el papel de madre, hija y consejera espiritual, sensibles al dolor humano; dispuestas a transmitir fuerza y animo a los enfermos más allá de nuestros propios temores.

"El enfermero de hoy posee como principal particularidad la gestión de los cuidados, conservando la vida y reforzando la satisfacción de las necesidades, considerado el principal cuidador durante el proceso asistencial, viéndose involucrado en situaciones estresantes haciéndolo vulnerable a daños físicos o psicológicos" (4). A pesar de la situación adversa como la falta de equipos de protección personal, recarga laboral e incremento de la carga viral en los ambientes de hospitalización que nos expone al contagio; nos alienta saber que estamos unidos, que todos estamos luchando por salvar la vida de nuestros pacientes y que ellos cumplen responsablemente con las normas dictadas por el gobierno para cuidar su salud y el de su familia. A pesar de que parte de la población y autoridades no valoran nuestros esfuerzos, es gratificante escuchar a personas que reconocen la abnegada labor desempeñada, motivándonos a continuar luchando contra esta pandemia. 
"Según la Organización Panamericana de la Salud, el miedo, la preocupación y el estrés son respuestas normales cuando nos enfrentamos a lo desconocido o a situaciones de crisis sobre todo en el contexto de la pandemia COVID-19. En esta pandemia aunado al temor de contraer el COVID-19, se suman los esfuerzos por frenar la propagación del virus, ocasionando un impacto social que altera nuestras vidas. Esta nueva realidad de distanciamiento físico, el trabajo desde el hogar, el desempleo temporal, la educación de los niños en el hogar y la falta de contacto físico con los seres queridos y amigos, provoca estrés que repercute en nuestra salud física y mental" (5). Muchas enfermeras sentimos temor y nos hemos visto en la imperiosa necesidad de aislarnos de nuestra familia, por el temor a contagiarlos. ¿Quién cuidará de nosotros cuando nos diagnostican el COVID 19?, hay que ser empáticos y pensemos que como seres humanos sentimos dolor y también se está en riesgo de enfermar. Somos enfermeros por vocación y seguiremos enfrentando cada turno de guardia con ánimo, entusiasmo, esperanza y compasión, orando para que Dios nos proteja y podamos regresar al lado de nuestra familia sin temor a contagiarlos; elegimos esta profesión para cuidar y salvar vidas, aunque muchas vidas se perderán irreparablemente durante esta pandemia.

Finalmente, como reflexión exhortar a la población a mantener la responsabilidad social que se muestra en el respeto y cumplimiento de las normas de bioseguridad: aislamiento social voluntario, uso correcto de la mascarilla y lavado de manos; asimismo mantengámonos unidos con mucha fe de que saldremos victoriosos de esta pandemia que ha enlutado nuestro querido Perú, y que enfermería siempre estará presente salvando vidas como lo hizo Florence Nightingale pionera de la Enfermería, durante la guerra de Crimea.

\section{REFERENCIAS BIBLIOGRÁFICAS.}

1. Wikipedia. COVID 19 (Internet). 2020 (Citado el 26 de Julio del 2020). Disponible en: https://es.wikipedia.org/wiki/COVID-19\#cite note-12

2. Acosta G, Escobar G, et al. Caracterización de pacientes con covid-19 grave atendidos en un hospital de referencia nacional del Perú. Rev Peru Med Exp Salud Publica. 2020;37(2):253-8.

3. Vargas A. Impacto de la epidemia del Coronavirus (COVID-19) en la salud mental del personal de Salud y en la población general de China. Rev Neuropsiquiatr. 2020; 83(1):51-56.

4. Zambrano C, Díaz H, Gómez G, et al. Acto en la salud mental de la (del) enfermera(o) que otorga cuidados en situaciones estresantes. Rev. Ciencia y enfermería. 2016, 21(1): 45-53.

5. Organización Panamericana de la Salud. Consideraciones psicosociales y de salud mental durante el brote de COVID-19 (internet). 2020 (Citado el 22 de julio del 2020). Disponible en: https://www.paho.org/es/salud-mental-covid-19 